\title{
Experimental and numerical analysis of web stiffened cold-formed steel channel column with various types of edge stiffener
}

\author{
P. Manikandan ${ }^{1} \cdot$ S. Balaji ${ }^{2} \cdot$ S. Sukumar ${ }^{3} \cdot$ M. Sivakumar ${ }^{4}$
}

Received: 21 September 2016/ Accepted: 17 March 2017/Published online: 5 April 2017

(c) The Author(s) 2017. This article is an open access publication

\begin{abstract}
This paper presents the strength and behaviour of web stiffened cold formed steel channel column with various types of edge stiffener under axial compression. An accurate finite element model is developed to simulate the tests results of the proposed section. The finite element model is verified by the test results and good correlation is achieved. The failure modes local, distortional, flexural buckling as well as the interaction between these modes is found in this study. The column strength predicted from the parametric study is compared with the nominal strength calculated by using the direct strength method for cold formed steel members. The reliability of this method is evaluated and suitable modification factor is proposed.
\end{abstract}

Keywords Axial loading - Direct strength method - Edge stiffener · Finite element model · Intermediate web stiffener

P. Manikandan

lp_mani@yahoo.com

S. Balaji

er.sbalaji@yahoo.co.in

S. Sukumar

sukumar_237@yahoo.co.in

1 Department of Civil Engineering, Sona College of Technology, Salem, Tamil Nadu, India

2 Kongu Engineering College, Erode, Tamil Nadu, India

3 Department of Civil Engineering, Government College of Engineering, Salem, Tamil Nadu, India

4 Vishwa Infrastructures \& Services Pvt Ltd, Ahmadabad, India

\section{Introduction}

Yielding, local buckling, distortional buckling, global buckling and interactive failure of these modes may affect the strength and behaviour of the cold-formed steel (CFS) section under compression. Conventionally, the effective width method (EWM) was more familiar with the design of CFS compression members. However, EWM involves tedious and iterative calculations for the design of CFS compression members. Therefore, the direct strength method (DSM) has been recently included in the North American Specification (AISI-2007) for the design of CFS compression members. The interactive buckling modes decrease the strength of the member to a value below the strength under the independent buckling modes. The aim of this study is to evaluate the accuracy of the DSM for the interactive failure.

\section{Review of literature}

A brief review of literature on the ultimate strength and buckling modes of web stiffened cold formed steel channel column with various types of edge stiffeners are presented here. Kwon and Hancock (1992) was the first to publish a paper describing the interaction between local and distortional buckling of the intermediate cold-formed steel thinwalled sections. Very recently, the interactive behaviour of lipped channel columns with and without intermediate web stiffeners has fascinated several researchers. Young and Yan (2002) and Yan and Young (2002) discussed local and distortional buckling of plain channel with upright and complex edge stiffener under axial compression. Experimental investigations on stiffened lipped channels by Yang and Hancock (2004), by Yap and Hancock (2008) on an 
Table 1 Material properties of steel

\begin{tabular}{llll}
\hline $\begin{array}{l}\text { Modulus of elasticity } \\
E(\mathrm{MPa})\end{array}$ & $\begin{array}{l}\text { Yield stress } \\
f_{y}(\mathrm{MPa})\end{array}$ & $\begin{array}{l}\text { Yield stress } \\
f_{U}(\mathrm{MPa})\end{array}$ & Elongation (\%) \\
\hline $1.98 \mathrm{E} 5$ & 273 & 481 & 19.5 \\
\hline
\end{tabular}

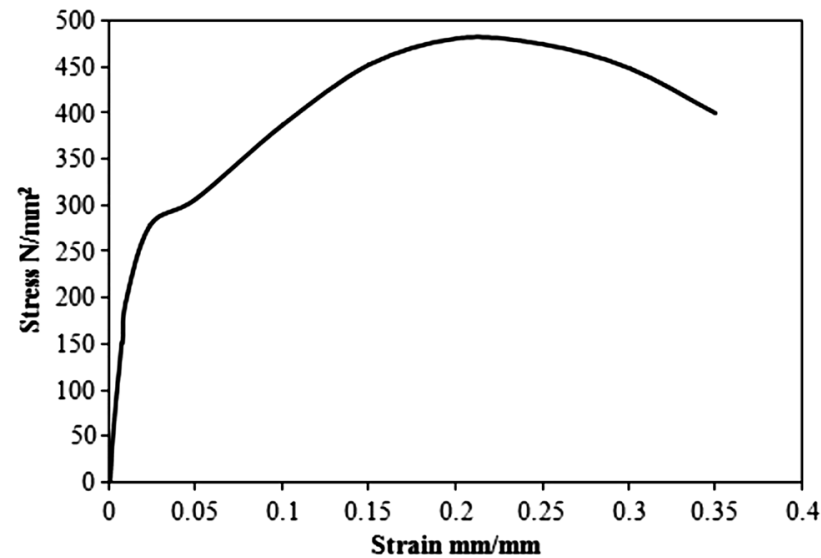

Fig. 1 Stress-strain behaviour of tensile coupons

complex high-strength cold-formed cross-shaped steel column, by Kwon et al. (2009) on an cold-formed simple lipped channels and lipped channels with intermediate stiffeners in the flanges and web, by Yap and Hancock (2011) on an web-stiffened high strength steel cold-formed lipped channel columns. Local-distortional buckling mode interactions of lipped channel columns were discussed by Young et al. (2013), He et al. (2014) Martins et al. (2015) and Manikandan and Arun (2016). Local, distortional and flexural interaction of channels column were reported by Dinis and Camotim (2011) and Wang et al. (2016). From the review of literature it is observed that, results on strength and buckling behaviour of cold-formed steel channel column with intermediate web stiffener is scattered. Hence in this study, web stiffened cold formed steel channel columns with various types of edge stiffeners are selected.

Totally, six cold formed steel columns with different cross-section geometry are tested and results are compared

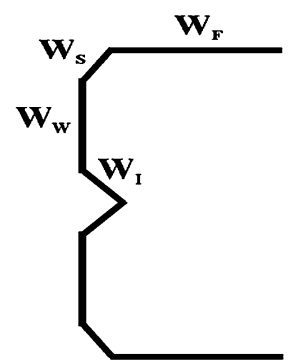

(a) WSC

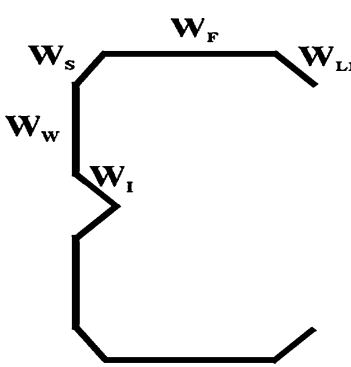

(b) WSC-IE

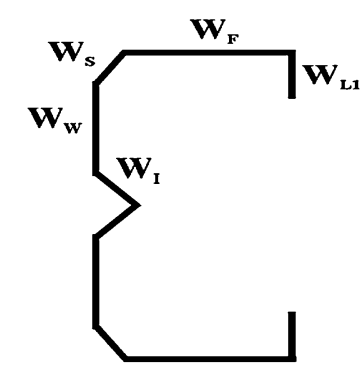

(c) WSC-UE

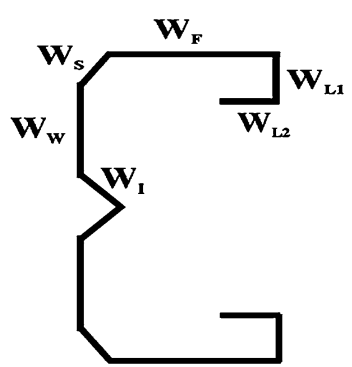

(d) WSC-CE

Fig. 2 Section geometry with acronym 
Table 2 Details of specimen

\begin{tabular}{lllllllll}
\hline $\begin{array}{l}\text { Specimen } \\
\text { labels }\end{array}$ & $\begin{array}{l}\text { Slenderness } \\
\text { ratio }(\lambda)\end{array}$ & \multicolumn{9}{l}{ Specimen dimensions (mm) } & & & \\
\cline { 3 - 9 } & & $t$ & $W_{w}$ & $W_{I}$ & $W_{s}$ & $W_{F}$ & $W_{L 1}$ & $W_{L 2}$ \\
\hline WSC- $\lambda$ & 50 & 1.6 & 50 & 15 & 15 & 70 & - & - \\
WSC-IE- $\lambda$ & 50 & 1.6 & 50 & 15 & 15 & 55 & 15 & - \\
WSC-UE- $\lambda$ & 30 & 1.6 & 50 & 15 & 15 & 55 & 15 & - \\
WSC-UE- $\lambda$ & 40 & 1.6 & 50 & 15 & 15 & 55 & 15 & - \\
WSC-UE- $\lambda$ & 50 & 1.6 & 50 & 15 & 15 & 55 & 15 & - \\
WSC-CE- $\lambda$ & 50 & 1.6 & 50 & 15 & 15 & 40 & 15 & 15 \\
WSC1-UE- $\lambda$ & $20-120$ & 1.6 & 26 & 15 & 15 & 65 & 15 & - \\
WSC2-UE- $\lambda$ & $20-120$ & 1.6 & 45 & 15 & 15 & 41 & 15 & - \\
WSC-CE-F270- $\lambda$ & $20-120$ & 2.0 & 60 & 20 & 18 & 40 & 20 & 15 \\
WSC-CE-F350- $\lambda$ & $20-120$ & 2.0 & 60 & 20 & 18 & 40 & 20 & 15 \\
WSC-CE-F550- $\lambda$ & $20-120$ & 2.0 & 60 & 20 & 18 & 40 & 20 & 15 \\
\hline
\end{tabular}

Table 3 Observation of test results

\begin{tabular}{|c|c|c|c|c|}
\hline \multirow[t]{2}{*}{ Specimen labels } & \multicolumn{2}{|c|}{ Ultimate load $(\mathrm{kN})$} & \multirow{2}{*}{$\begin{array}{l}P_{\mathrm{EXP}} \\
P_{\mathrm{ANSYS}}\end{array}$} & \multirow{2}{*}{$\begin{array}{l}\text { Mode of } \\
\text { failures }\end{array}$} \\
\hline & $P_{\text {EXP }}$ & $P_{\mathrm{ANSYS}}$ & & \\
\hline WSC $-\lambda 50$ & 37.2 & 39.18 & 0.95 & $\mathrm{~L}$ \\
\hline WSC-IE- $\lambda 50$ & 78.05 & 75.00 & 1.04 & $\mathrm{~L}+\mathrm{D}$ \\
\hline WSC-UE- $\lambda 30$ & 93.11 & 96.81 & 0.96 & $\mathrm{~L}+\mathrm{D}$ \\
\hline WSC-UE- $\lambda 40$ & 98.23 & 103.65 & 0.95 & $\mathrm{~L}+\mathrm{D}$ \\
\hline WSC-UE- $\lambda 50$ & 101.23 & 104.47 & 0.97 & $\mathrm{~L}+\mathrm{D}$ \\
\hline WSC-CE- $\lambda 50$ & 102.56 & 103.88 & 0.99 & $\mathrm{~L}+\mathrm{FB}$ \\
\hline Mean & & & 0.98 & \\
\hline Standard deviation & & & 0.03 & \\
\hline
\end{tabular}

$L$ local buckling, $D$ distortional buckling, $F B$ flexural buckling

parametric study, four different types of specimen labeling rules are used and also it is discussed in the appropriate section. The following specimen labels are used for the verification of finite element analysis and evaluate the effectiveness of the proposed cross section as shown in Fig. 2. For an example, the label "WSC-IE- $\lambda 50$ ", the first term defines the type of cross section [web stiffened channel (WSC)], the second term defines the types of edge stiffener [inclined edge stiffener (IE), upright edge stiffener (UE) and complex edge stiffener (CE)] and last term defines the slenderness ratio of the member $(\lambda 50 ; \lambda$ is the symbol for slenderness ratio and 50 for magnitude of slenderness ratio).

\section{Selection of section and test setup}

The selected cross-section profile with corresponding nomenclature is shown in Fig. 2. The dimension of the selected cross section is presented in Table 2 and also it is met with the pre-qualified column dimensions of the cold formed steel section. Totally, six specimens are tested with a nominal overall slenderness ratio ranging from 30

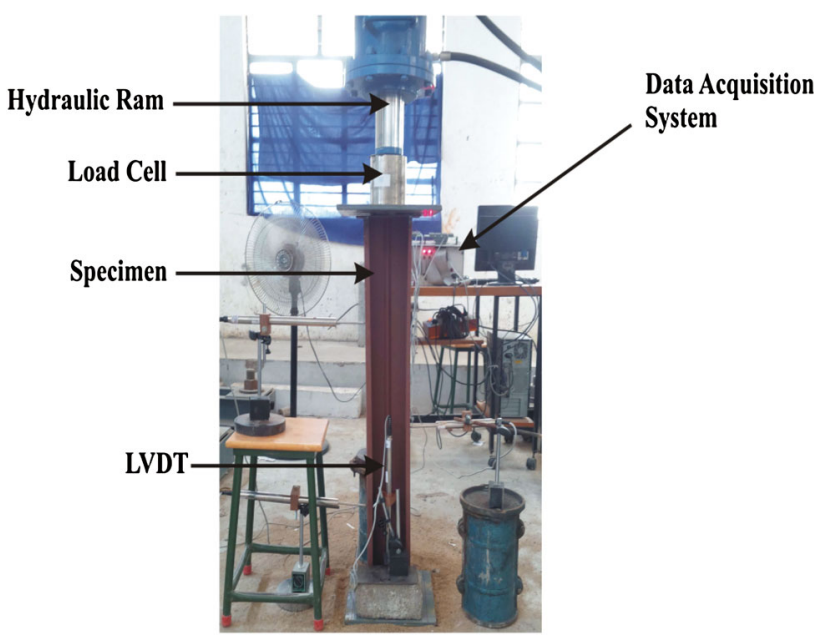

Fig. 3 Experimental set-up
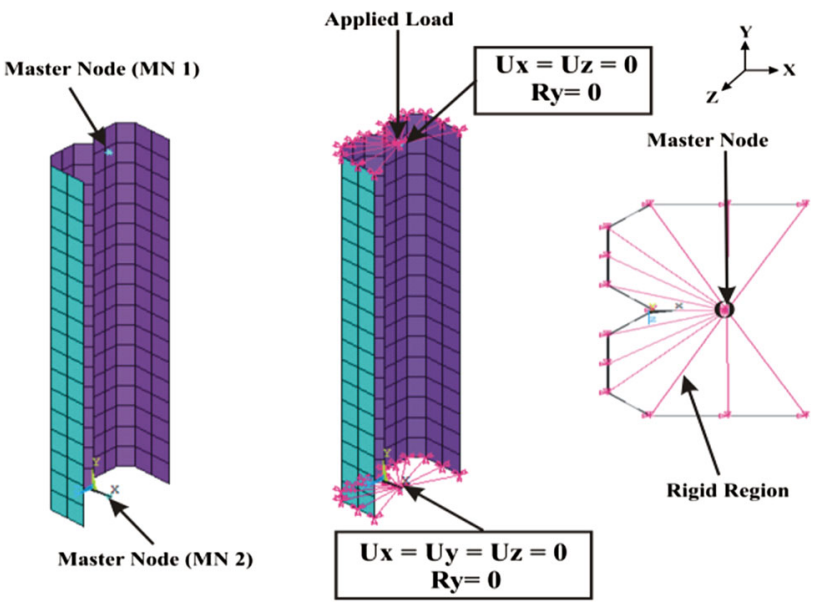

Fig. 4 Details of finite element model

to 50. All the specimens are fabricated from locally available $1.6 \mathrm{~mm}$ thick cold rolled steel sheets by using the brake-pressed operation. All the specimens are tested 
a

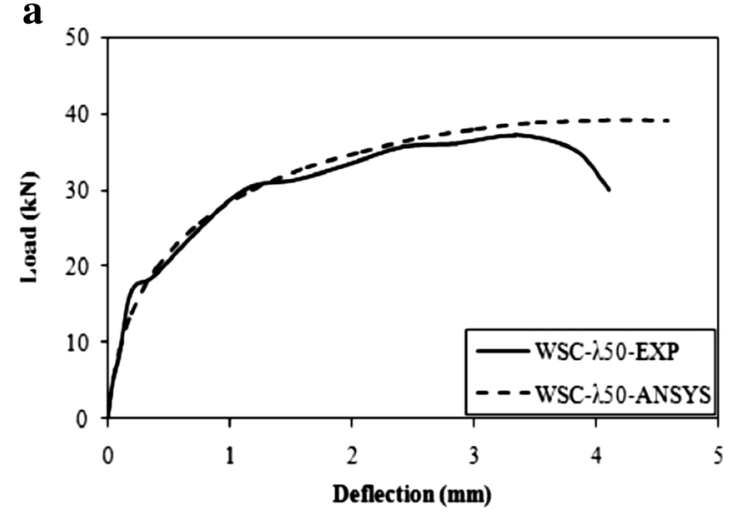

c

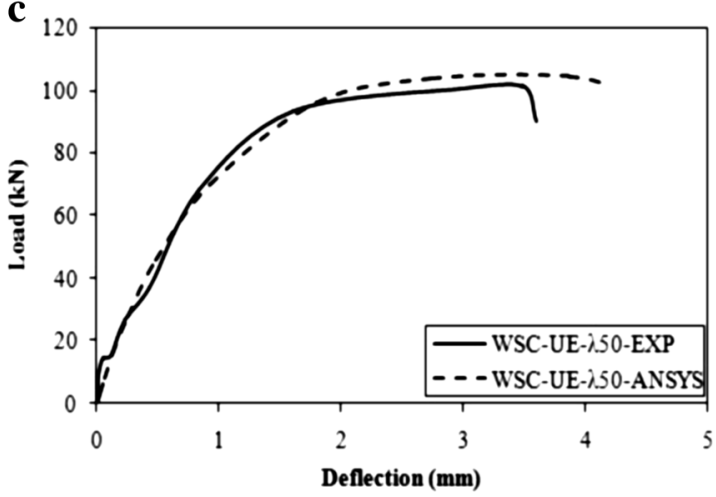

b

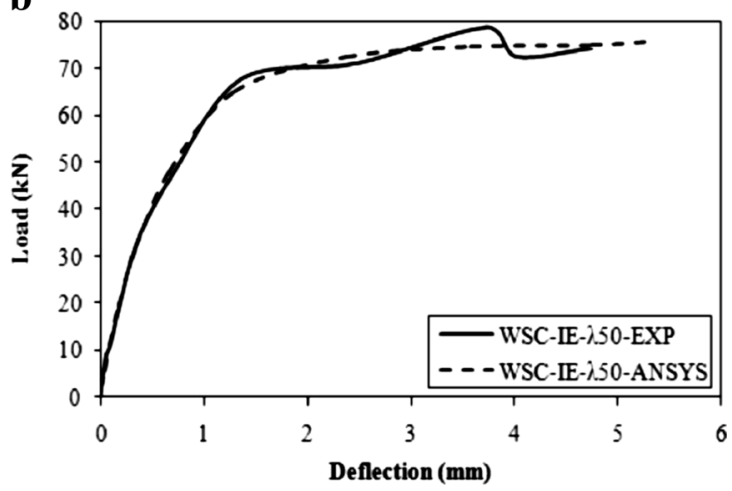

d

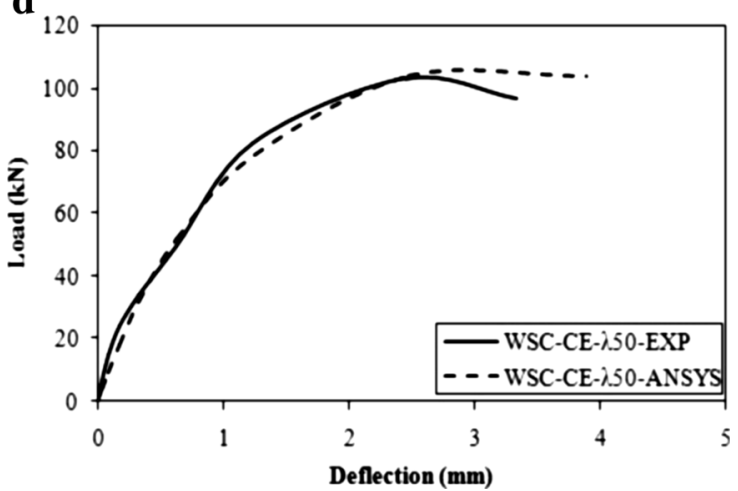

Fig. 5 Comparison of load deflection curve between test and finite element analysis

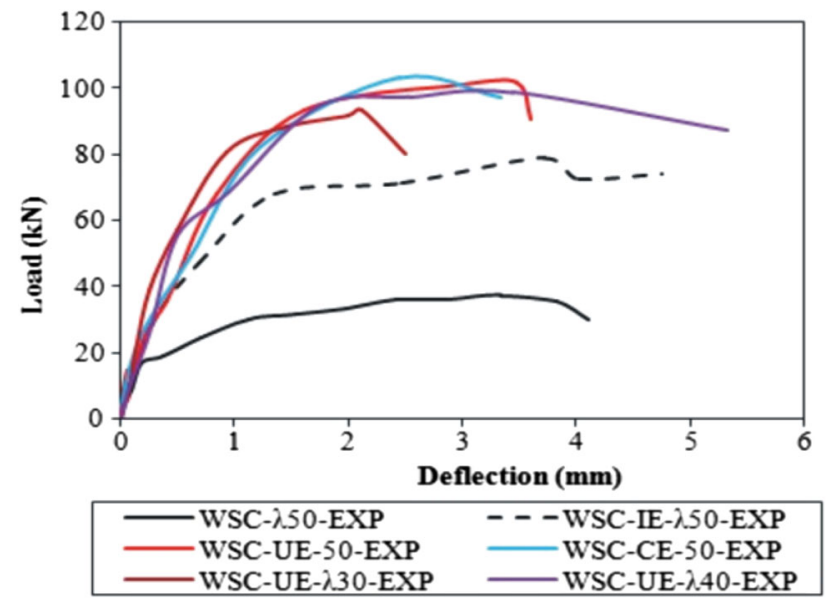

Fig. 6 Load deflection curve for tested specimens

under axial loading with subjected to pinned end conditions. To achieve the uniform compressive force over the entire cross section of the column, the thick steel plates are welded at each end of the column. The loads are applied at the C.G of the section by using the load cell and before applying the load, the verticality of the column is verified. Before positioning the data acquisition (LVDT), a pre-quantity of $5 \mathrm{kN}$ load is applied to the specimen. The entire load-deflection response is monitored by using the data acquisition system. Observation of test results is presented in Table 3. The experimental set-up is illustrated in Fig. 3.

\section{Finite element analyses}

Numerical investigation is carried out by using the finite element analysis software package ANSYS. Shell 181 element is used for modeling the specimen. To minimizing the computational time and improving the accuracy of the finite element analysis, a mesh sensitive analysis is carried out. From the mesh sensitive analysis, a mesh size of $100 \mathrm{~mm}^{2}$ is used for entire study. Residual stress (He et al. (2014) and GB 50018-2002 (2002)) and effect of cold forming process (Yan and Young 2002) are ignoring in the finite element (FE) model. Master nodes (MN1 and MN2) are generated by using the Structural 3D element available from the ANSYS material library. Rigid regions are generated through the master node and master node are coincides at the C.G of the section. Load and end boundary conditions are applied through the master nodes. All the specimens are analyzed under axial loading with pinned end conditions. Detailed finite element modeling are illustrated in Fig. 4. Material imperfections are incorporated in the FE model. Material properties are 
Fig. 7 Comparison of failure modes a WSC-IE- $\lambda 50$, b WSCUE- $\lambda 50, \mathbf{c}$ WSC-UE- $\lambda 40, \mathbf{d}$ WSC-CE- $\lambda 50$
Table 4 Effect of thickness variations

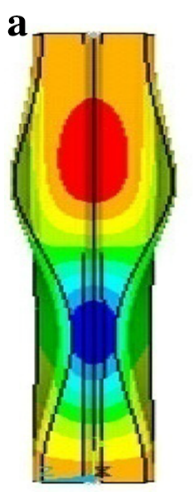

c

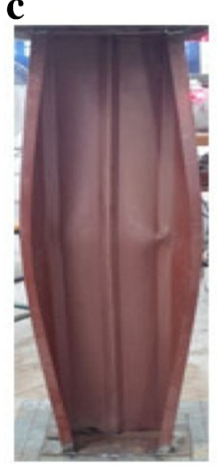

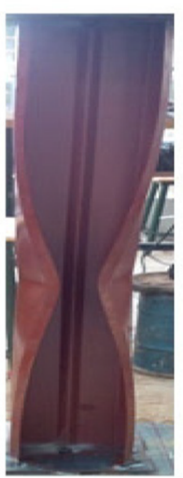

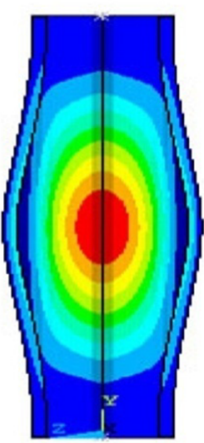

b
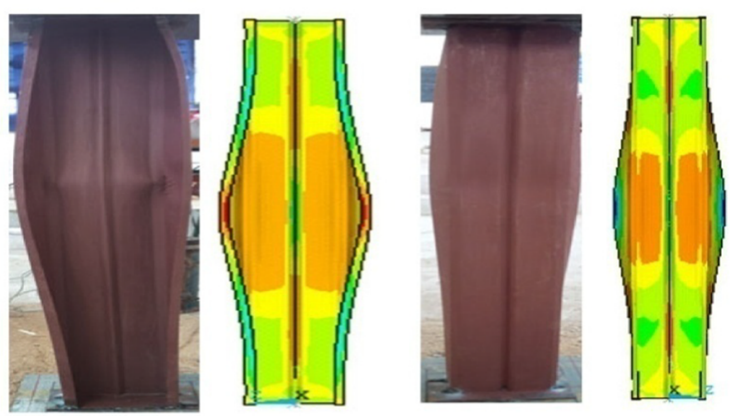

d
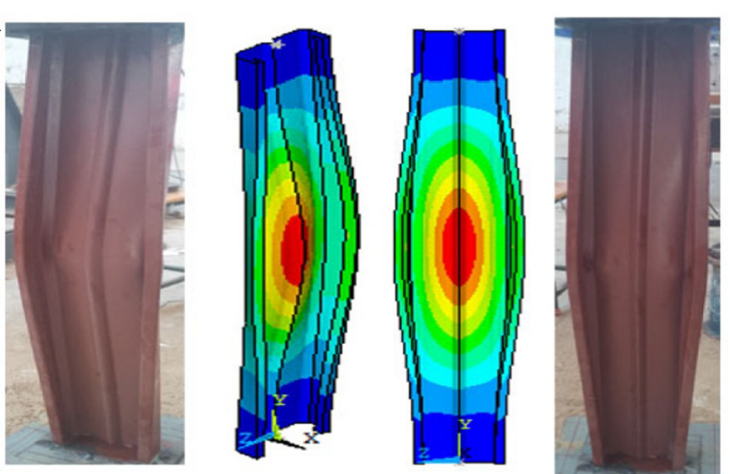

\begin{tabular}{|c|c|c|c|c|c|c|c|c|c|c|}
\hline \multirow[t]{2}{*}{ Specimen labels } & \multicolumn{7}{|c|}{ Section dimension $(\mathrm{mm})$} & \multicolumn{2}{|c|}{ Ultimate load $(\mathrm{kN})$} & \multirow{2}{*}{$\begin{array}{l}P_{\mathrm{ANSYS}} \\
P_{n, \mathrm{DSM}}\end{array}$} \\
\hline & $t$ & $W_{w}$ & $W_{I}$ & $W_{s}$ & $W_{F}$ & $W_{L 1}$ & $W_{L 2}$ & $P_{\text {ANSYS }}$ & $P_{n, \mathrm{DSM}}$ & \\
\hline WSC-T1.6- 250 & 1.6 & 50 & 15 & 15 & 70 & - & - & 41.77 & 48.35 & 0.86 \\
\hline WSC-T2- $\lambda 50$ & 2.0 & 50 & 15 & 15 & 70 & - & - & 60.06 & 76.31 & 0.79 \\
\hline WSC-T3- $\lambda 50$ & 3.0 & 50 & 15 & 15 & 70 & - & - & 123.00 & 191.53 & 0.64 \\
\hline WSC-IE-T1.6- $\lambda 50$ & 1.6 & 50 & 15 & 15 & 55 & 15 & - & 75.00 & 82.59 & 0.91 \\
\hline WSC-IE-T2- $\lambda 50$ & 2.0 & 50 & 15 & 15 & 55 & 15 & - & 103.37 & 115.04 & 0.90 \\
\hline WSC-IE-T3- $\lambda 50$ & 3.0 & 50 & 15 & 15 & 55 & 15 & - & 179.37 & 211.19 & 0.85 \\
\hline WSC-UE-T1.6- $\lambda 50$ & 1.6 & 50 & 15 & 15 & 55 & 15 & - & 98.63 & 93.52 & 1.05 \\
\hline WSC-UE-T2- $\lambda 50$ & 2.0 & 50 & 15 & 15 & 55 & 15 & - & 109.31 & 127.91 & 0.85 \\
\hline WSC-UE-T3- $\lambda 50$ & 3.0 & 50 & 15 & 15 & 55 & 15 & - & 180.52 & 207.2 & 0.87 \\
\hline WSC-CE-T1.6- $\lambda 50$ & 1.6 & 50 & 15 & 15 & 40 & 15 & 15 & 103.87 & 94.35 & 1.10 \\
\hline WSC-CE-T2- $\lambda 50$ & 2.0 & 50 & 15 & 15 & 40 & 15 & 15 & 124.42 & 137.98 & 0.90 \\
\hline WSC-CE-T3- 250 & 3.0 & 50 & 15 & 15 & 40 & 15 & 15 & 185.43 & 204.21 & 0.91 \\
\hline Mean & & & & & & & & & & 0.89 \\
\hline Standard deviation & & & & & & & & & & 0.12 \\
\hline
\end{tabular}

directly obtained from the coupon test and bilinear material properties are used. Before the tests, the section dimensions of each specimen are measured at the midheight and both ends by using the vernier caliper. During the measurements of imperfection, it is observed that the geometric imperfections and rounded response are not observed. Because, all the specimens are fabricated using the latest computerized cutting and sharp folding press braking machine. The sharp cutting edges provide right angular edge only. Based on the test results, the effect of cold forming process has been ignored in the FE model. Two types of analysis are carried out. First is Eigen buckling analysis and second is non linear large displacement static buckling analysis. The main purpose of the Eigen buckling analysis is to find possible buckling modes. 
Table 5 Comparison of FEA and DSM results- Specimen with upright edge stiffener

\begin{tabular}{|c|c|c|c|c|c|c|}
\hline \multirow[t]{2}{*}{ Specimen labels } & \multicolumn{3}{|c|}{ Ultimate load $(\mathrm{kN})$} & \multirow{2}{*}{$\begin{array}{l}P_{\mathrm{ANSYS}} \\
P_{n, \mathrm{DSM}}\end{array}$} & \multirow{2}{*}{$\begin{array}{l}P_{\text {ANSYS }} \\
P_{\text {prop }}\end{array}$} & \multirow[t]{2}{*}{ Failure mode } \\
\hline & $P_{\text {ANSYS }}$ & $P_{n, \mathrm{DSM}}$ & $P_{\text {prop }}$ & & & \\
\hline WSC1-UE- $\lambda 20$ & 83.110 & 80.68 & 78.64 & 1.03 & 1.06 & $\mathrm{~L}+\mathrm{DB}$ \\
\hline WSC1-UE- $\lambda 30$ & 82.090 & 80.68 & 78.64 & 1.02 & 1.04 & $\mathrm{~L}+\mathrm{DB}$ \\
\hline WSC1-UE- $\lambda 40$ & 77.517 & 80.68 & 78.64 & 0.96 & 0.99 & $\mathrm{~L}+\mathrm{DB}$ \\
\hline WSC1-UE- $\lambda 50$ & 76.420 & 80.68 & 78.64 & 0.95 & 0.97 & $\mathrm{~L}+\mathrm{DB}$ \\
\hline WSC1-UE- $\lambda 60$ & 72.010 & 80.68 & 78.64 & 0.89 & 0.92 & $\mathrm{~L}+\mathrm{DB}$ \\
\hline WSC1-UE- $\lambda 70$ & 69.100 & 80.68 & 78.64 & 0.86 & 0.88 & $\mathrm{~L}+\mathrm{DB}$ \\
\hline WSC1-UE- $\lambda 80$ & 67.930 & 74.90 & 74.06 & 0.91 & 0.92 & $\mathrm{~L}+\mathrm{DB}$ \\
\hline WSC2-UE- $\lambda 20$ & 96.560 & 81.53 & 79.31 & 1.18 & 1.22 & $\mathrm{~L}+\mathrm{DB}$ \\
\hline WSC2-UE- $\lambda 30$ & 92.010 & 81.53 & 79.31 & 1.13 & 1.16 & $\mathrm{~L}+\mathrm{DB}$ \\
\hline WSC2-UE- $\lambda 40$ & 90.113 & 81.53 & 79.31 & 1.11 & 1.14 & $\mathrm{~L}+\mathrm{DB}$ \\
\hline WSC2-UE- $\lambda 50$ & 89.600 & 81.53 & 79.31 & 1.10 & 1.13 & $\mathrm{~L}+\mathrm{DB}$ \\
\hline WSC2-UE- $\lambda 60$ & 80.080 & 81.53 & 79.31 & 0.98 & 1.01 & $\mathrm{~L}+\mathrm{DB}$ \\
\hline WSC2-UE- $\lambda 70$ & 79.540 & 81.53 & 79.31 & 0.98 & 1.00 & $\mathrm{~L}+\mathrm{DB}$ \\
\hline WSC1-UE- $\lambda 90$ & 65.320 & 68.66 & 69.11 & 0.95 & 0.95 & $\mathrm{~L}+\mathrm{FB}$ \\
\hline WSC1-UE- $\lambda 100$ & 64.320 & 61.85 & 63.71 & 1.04 & 1.01 & $\mathrm{~L}+\mathrm{FB}$ \\
\hline WSC1-UE- $\lambda 110$ & 60.110 & 55.14 & 58.39 & 1.09 & 1.03 & $\mathrm{~L}+\mathrm{FB}$ \\
\hline WSC1-UE- $\lambda 120$ & 53.880 & 49.60 & 53.99 & 1.09 & 1.00 & $\mathrm{~L}+\mathrm{FB}$ \\
\hline WSC2-UE- $\lambda 90$ & 74.180 & 73.03 & 72.57 & 1.02 & 1.02 & $\mathrm{~L}+\mathrm{FB}$ \\
\hline WSC2-UE- $\lambda 100$ & 64.770 & 67.17 & 67.93 & 0.96 & 0.95 & $\mathrm{~L}+\mathrm{FB}$ \\
\hline WSC2-UE- $\lambda 110$ & 57.180 & 62.55 & 64.26 & 0.91 & 0.89 & $\mathrm{~L}+\mathrm{FB}$ \\
\hline WSC2-UE- $\lambda 120$ & 49.690 & 56.72 & 59.64 & 0.88 & 0.83 & $\mathrm{~L}+\mathrm{FB}$ \\
\hline WSC2-UE- $\lambda 80$ & 76.880 & 78.77 & 77.12 & 0.98 & 1.00 & $\mathrm{FB}+\mathrm{DB}$ \\
\hline Mean & & & & 1.00 & 1.00 & \\
\hline Standard deviation & & & & 0.09 & 0.09 & \\
\hline
\end{tabular}

$L$ local buckling, $D$ distortional buckling, $F T$ flexural torsional buckling

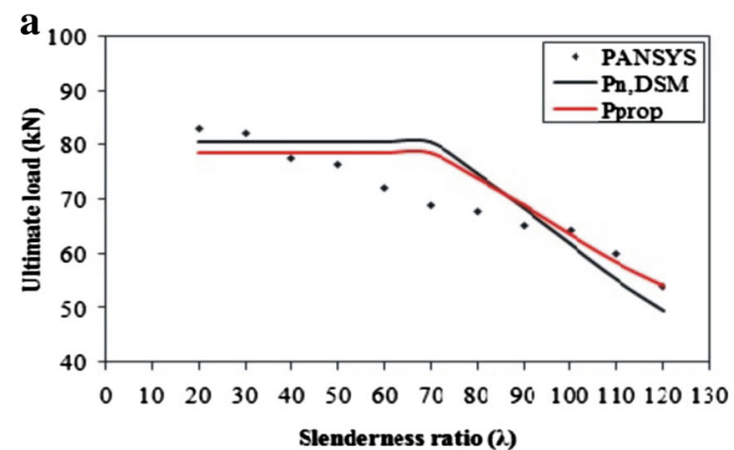

Fig. 8 Comparison of results—-specimen with upright edge stiffener a WSC1-UE, b WSC2-UE

\section{Test verification}

From the Fig. 5, it is observed that the strength of the section increases with modifying the types of edge stiffeners. The comparison of load deflection curves and failure modes between test and FEA are shown in Figs. 6 and 7, respectively. In this experimental study, interactive failure

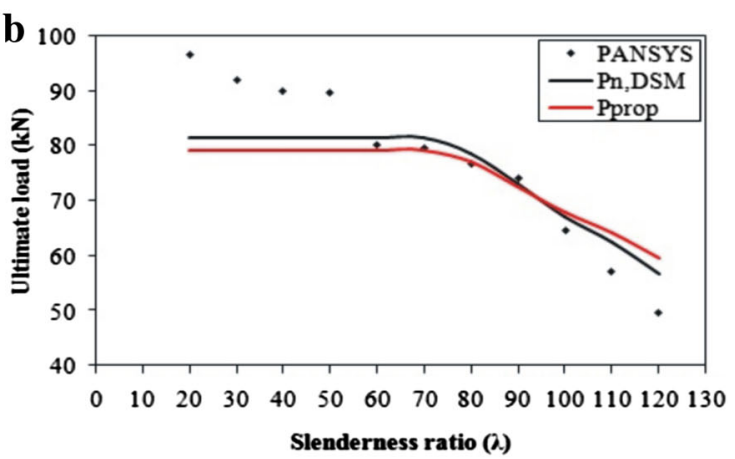

modes are observed such as local and distortional buckling and local and flexural buckling and also it is confirmed with FEA (Fig. 7). Totally, six specimens are tested and results are compared with finite element analysis (Table 3). The mean and standard deviation of $P_{\mathrm{EXP}}$ and $P_{\mathrm{ANSYS}}$ are 0.98 and 0.03 , respectively. The similarity of Figs. 5 and 7 demonstrates the consistency of the FEA predictions. 
Fig. 9 Load-deflection curve WSC-CE-F270- $\lambda$ series

Fig. 10 Failure modes of WSC-CE-F270- $\lambda$ series

\section{Parametric studies}

The established FE model is used for an extensive parametric study. From this test results it is observed that, the WSC-UE and WSC-CE series provides a better performance compared to all other specimens. Hence, a detailed parametric study is carried out on the WSC-UE and WSC-CE series of specimens by using the verified finite element FE model. The parametric study included 67 specimens that consisted of 9 series as shown in Table 2. All the results are compared with the Direct Strength Specifications (DSM) for cold formed steel structures.

\section{Theoretical investigation}

The nominal capacity of members in axial compression $\left(P_{n}\right.$, DSM $)$ shall be least of local buckling $\left(P_{n 1}\right)$, distortional buckling $\left(P_{n \mathrm{~d}}\right)$ and flexural torsional buckling $\left(P_{n \mathrm{e}}\right)$.
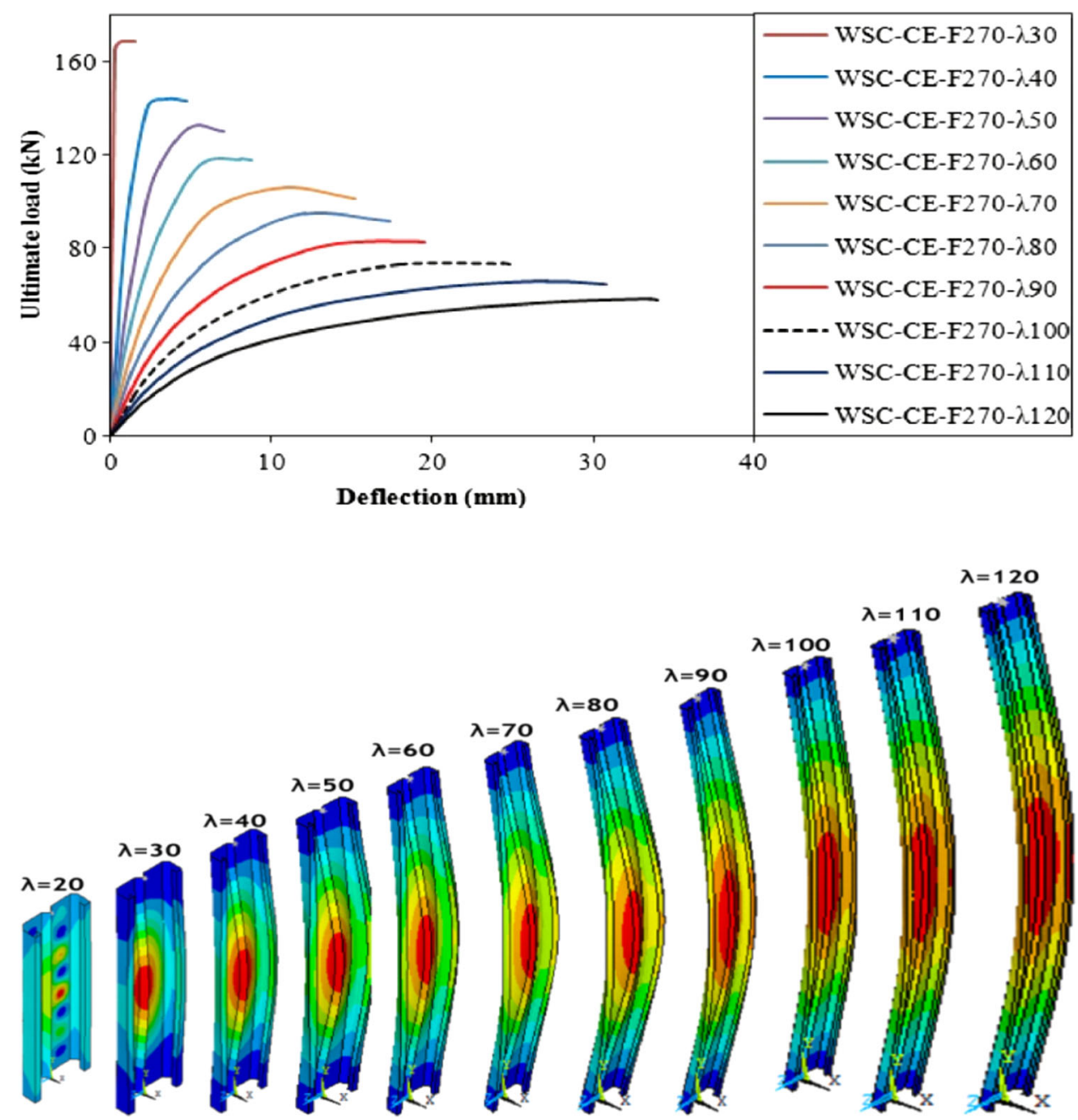

where $\lambda_{c}=\sqrt{P_{y} / P_{\text {cre }}}$ and $P_{\mathrm{y}}=A f_{y} \cdot P_{y}$ is the squash load.

$P_{n l}= \begin{cases}P_{n e} & \text { for } \lambda_{1} \leq 0.776 \\ \left(1-0.15\left(\frac{P_{c r l}}{P_{n e}}\right)^{0.4}\right)\left(\frac{P_{c r l}}{P_{n e}}\right) P_{n e} & \text { for } \lambda_{1}>0.776\end{cases}$

where $\lambda_{1}=\sqrt{P_{\mathrm{ne}} / P_{\mathrm{crl}}}$

$P_{n d}= \begin{cases}P_{y} & \text { for } \lambda_{d} \leq 0.561 \\ \left(1-0.25\left(\frac{P_{c r d}}{P_{y}}\right)^{0.6}\right)\left(\frac{P_{c r d}}{P_{y}}\right)^{0.6} P_{y} & \text { for } \lambda_{d}>0.561\end{cases}$

where $\lambda_{d}=\sqrt{P_{\mathrm{y}} / P_{\text {crd }}}$.

$P_{n, \mathrm{DSM}}=\operatorname{Minmum}\left(P_{n \mathrm{l}}, P_{n \mathrm{~d}}, P_{n \mathrm{e}}\right)$ 
Table 6 Comparison of FEA and DSM results- Specimen with complex edge stiffener

\begin{tabular}{|c|c|c|c|c|c|c|}
\hline \multirow[t]{2}{*}{ Specimen labels } & \multicolumn{3}{|c|}{ Ultimate load (kN) } & \multirow{2}{*}{$\begin{array}{l}P_{\mathrm{ANSYS}} \\
P_{n, \mathrm{DSM}}\end{array}$} & \multirow{2}{*}{$\begin{array}{l}P_{\text {ANSYS }} \\
P_{\text {prop }}\end{array}$} & \multirow[t]{2}{*}{ Failure mode } \\
\hline & $P_{\text {ANSYS }}$ & $P_{n, \mathrm{DSM}}$ & $P_{\text {prop }}$ & & & \\
\hline WSC-CE-F270- $\lambda 20$ & 158.28 & 174.23 & 152.82 & 0.91 & 1.04 & $\mathrm{~L}$ \\
\hline WSC-CE-F270- $\lambda 30$ & 153.66 & 164.75 & 145.31 & 0.93 & 1.06 & $\mathrm{D}+\mathrm{FB}$ \\
\hline WSC-CE-F270- $\lambda 40$ & 149.41 & 152.61 & 135.68 & 0.98 & 1.10 & $\mathrm{D}+\mathrm{FB}$ \\
\hline WSC-CE-F270- $\lambda 50$ & 131.64 & 138.73 & 124.67 & 0.95 & 1.06 & $\mathrm{D}+\mathrm{FB}$ \\
\hline WSC-CE-F270- $\lambda 60$ & 118.30 & 124.01 & 113.00 & 0.95 & 1.05 & $\mathrm{D}+\mathrm{FB}$ \\
\hline WSC-CE-F270- $\lambda 70$ & 106.29 & 109.24 & 101.29 & 0.97 & 1.05 & $\mathrm{D}+\mathrm{FB}$ \\
\hline WSC-CE-F270- $\lambda 80$ & 94.89 & 95.10 & 90.07 & 1.00 & 1.05 & $\mathrm{D}+\mathrm{FT}$ \\
\hline WSC-CE-F270- $\lambda 90$ & 83.16 & 81.98 & 79.67 & 1.01 & 1.04 & $\mathrm{D}+\mathrm{FT}$ \\
\hline WSC-CE-F270- $\lambda 100$ & 73.52 & 70.06 & 70.22 & 1.05 & 1.05 & $\mathrm{D}+\mathrm{FT}$ \\
\hline WSC-CE-F270- $\lambda 110$ & 65.37 & 59.91 & 62.17 & 1.09 & 1.05 & $\mathrm{D}+\mathrm{FT}$ \\
\hline WSC-CE-F270- $\lambda 120$ & 58.55 & 52.22 & 56.07 & 1.12 & 1.04 & $\mathrm{D}+\mathrm{FT}$ \\
\hline WSC-CE-F350- $\lambda 20$ & 261.37 & 230.14 & 197.16 & 1.14 & 1.33 & $\mathrm{~L}+\mathrm{FT}$ \\
\hline WSC-CE-F350- $\lambda 30$ & 223.49 & 223.42 & 191.83 & 1.00 & 1.17 & $\mathrm{~L}+\mathrm{FT}$ \\
\hline WSC-CE-F350- $\lambda 40$ & 221.02 & 214.35 & 184.64 & 1.03 & 1.20 & $\mathrm{~L}+\mathrm{FT}$ \\
\hline WSC-CE-F350- $\lambda 50$ & 200.34 & 203.41 & 175.96 & 0.98 & 1.14 & $\mathrm{D}+\mathrm{FB}$ \\
\hline WSC-CE-F350- $\lambda 60$ & 181.50 & 190.91 & 166.05 & 0.95 & 1.09 & $\mathrm{D}+\mathrm{FB}$ \\
\hline WSC-CE-F350- $\lambda 70$ & 164.34 & 177.39 & 155.33 & 0.93 & 1.06 & $\mathrm{D}+\mathrm{FB}$ \\
\hline WSC-CE-F350- $\lambda 80$ & 159.51 & 163.20 & 144.08 & 0.98 & 1.11 & $\mathrm{~L}+\mathrm{FB}$ \\
\hline WSC-CE-F350- $\lambda 90$ & 138.59 & 148.79 & 132.65 & 0.93 & 1.04 & $\mathrm{~L}+\mathrm{FB}$ \\
\hline WSC-CE-F350- $\lambda 100$ & 116.96 & 134.51 & 121.33 & 0.87 & 0.96 & $\mathrm{~L}+\mathrm{FB}$ \\
\hline WSC-CE-F350- $\lambda 110$ & 99.24 & 120.63 & 110.32 & 0.82 & 0.90 & $\mathrm{~L}+\mathrm{FB}$ \\
\hline WSC-CE-F350- $\lambda 120$ & 83.91 & 107.06 & 99.56 & 0.78 & 0.84 & $\mathrm{~L}+\mathrm{FB}$ \\
\hline WSC-CE-F550- $\lambda 20$ & 327.56 & 355.57 & 296.63 & 0.92 & 1.10 & $\mathrm{~L}+\mathrm{FT}$ \\
\hline 0WSC-CE-F550- $\lambda 30$ & 292.43 & 339.38 & 283.79 & 0.86 & 1.03 & $\mathrm{D}+\mathrm{FB}$ \\
\hline WSC-CE-F550- $\lambda 40$ & 257.33 & 318.12 & 266.93 & 0.81 & 0.96 & $\mathrm{D}+\mathrm{FT}$ \\
\hline WSC-CE-F550- $\lambda 50$ & 196.70 & 292.99 & 247.00 & 0.67 & 0.80 & $\mathrm{D}+\mathrm{FT}$ \\
\hline WSC-CE-F550- $\lambda 60$ & 193.60 & 265.32 & 225.06 & 0.73 & 0.86 & $\mathrm{D}+\mathrm{FT}$ \\
\hline WSC-CE-F550- $\lambda 70$ & 163.26 & 236.46 & 202.17 & 0.69 & 0.81 & $\mathrm{D}+\mathrm{FT}$ \\
\hline WSC-CE-F550- $\lambda 80$ & 137.54 & 207.50 & 179.21 & 0.66 & 0.77 & $\mathrm{D}+\mathrm{FT}$ \\
\hline WSC-CE-F550- $\lambda 90$ & 116.61 & 179.52 & 157.02 & 0.65 & 0.74 & $\mathrm{D}+\mathrm{FT}$ \\
\hline WSC-CE-F550- $\lambda 100$ & 99.45 & 153.32 & 136.24 & 0.65 & 0.73 & $\mathrm{D}+\mathrm{FT}$ \\
\hline WSC-CE-F550- $\lambda 110$ & 85.41 & 129.17 & 117.09 & 0.66 & 0.73 & $\mathrm{D}+\mathrm{FT}$ \\
\hline WSC-CE-F550- $\lambda 120$ & 75.91 & 109.64 & 101.60 & 0.69 & 0.75 & $\mathrm{D}+\mathrm{FT}$ \\
\hline Mean & & & & 0.89 & 0.99 & \\
\hline Standard deviation & & & & 0.15 & 0.15 & \\
\hline
\end{tabular}

$L$ local buckling, $D$ distortional buckling, $F T$ flexural torsional buckling, $F T$ flexural torsional buckling

\section{Effect of thickness variations}

In this parametric study, initially effects of thickness variation on all the series of sections are analyzed. The specimens are labeled such that the cross section shapes and thickness of the sections could be identified, as shown in Table 4. For an example, the label "WSC-IE-T1.6- $\lambda 50$ ", the first term defines the type of cross section [web stiffened channel (WSC)], the second term defines the types of edge stiffener [inclined edge stiffener (IE), upright edge stiffener (UE) and complex edge stiffener (CE)], third term defines the thickness $(T)$ of the specimen in $\mathrm{mm}$ and last term defines the slenderness ratio of the member $(\lambda 50 ; \lambda$ is the symbol for slenderness ratio and 50 for magnitude of slenderness ratio). The column strength obtained from the parametric study is exposed in Table 4. From this study, it is observed that the thickness of the section considerably affects the strength of the section. 

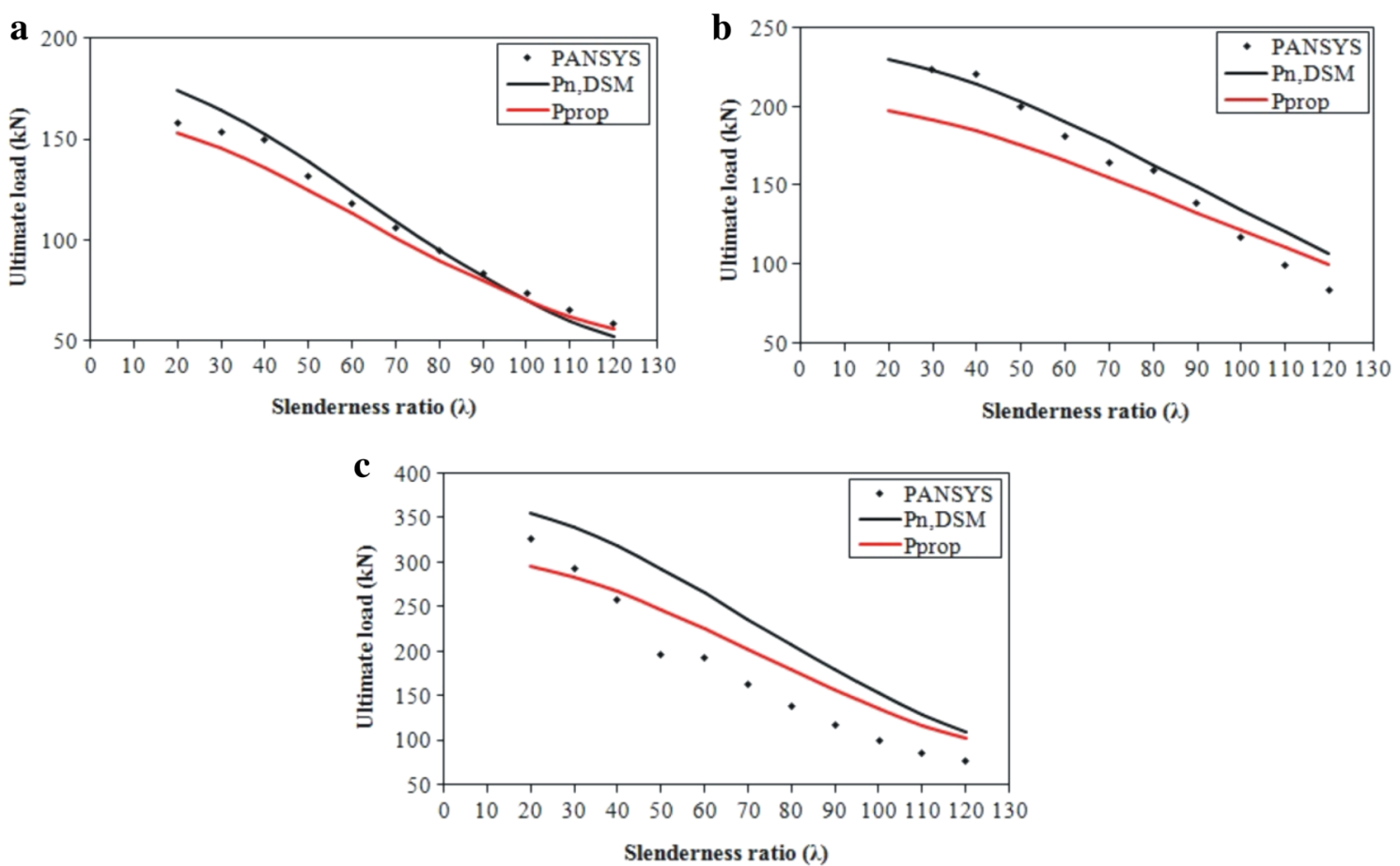

Fig. 11 Comparison of results. Specimen with complex edge stiffener a WSC-CE-F270, b WSC-CE-F350, c WSC-CE-F550

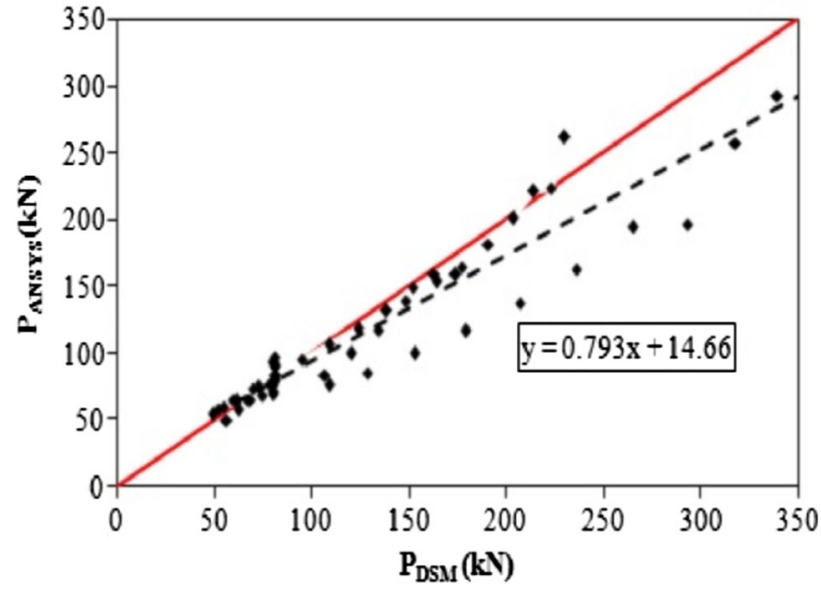

Fig. 12 Relation between FEA and DSM results

\section{Behaviour of web stiffened channel with upright edge stiffener}

Two series of WSC-UE (WSC1-UE and WSC2-UE) with 11 slenderness variation $(\lambda=20,30,40,50,60,70,80,90$, 100,110 and 120) gave the 22 cross-sectional geometries. All the specimens are failed by interactive mode of buckling. The observed failure modes are mixed local and distortional buckling, mixed flexural and distortional buckling and mixed local and flexural buckling. The comparison between FEA and DSM are presented in Table 5 and Fig. 8. From this study, it is observed that the
Table 7 Verification of proposed design equation

\begin{tabular}{lllll}
\hline $\begin{array}{l}\text { Specimen ID as per } \\
\text { literature }\end{array}$ & $P_{\text {EXP }}(\mathrm{kN})$ & $P_{\text {DSM }}(\mathrm{kN})$ & $P_{\text {prop }}(\mathrm{kN})$ & $\begin{array}{l}P_{\text {EXP }} \\
P_{\text {prop }}\end{array}$ \\
\hline WSC15-1000-1[3] & 170.50 & 198.60 & 172.15 & 0.99 \\
WSC15-1000-2[3] & 172.80 & 205.70 & 177.78 & 0.97 \\
SWC700-1[5] & 267.80 & 283.50 & 239.48 & 1.12 \\
SWC700-2[5] & 231.60 & 284.30 & 240.11 & 0.96 \\
SWC700-3[5] & 260.50 & 283.80 & 239.71 & 1.09 \\
Mean & & & & 1.03 \\
Standard deviation & & & & 0.07 \\
\hline
\end{tabular}

DSM is producing the unconservative results for the interactive failure modes of the intermediate slenderness ranges of web stiffened channel with upright edge stiffener.

\section{Behaviour of web stiffened channel with complex edge stiffener}

Three series of WSC-CE section (WSC-CE-F270- $\lambda$, WSCCE-F350- $\lambda$ and WSC-CE-F550- $\lambda$ ) with 11 slenderness variation $(\lambda=20,30,40,50,60,70,80,90,100,110$ and 120) gave the 33 cross-sectional geometries. For as an example, load deflection curve and the failure mode of WSC-CE-F270- $\lambda$ series of specimen are shown in Figs. 9 and 10 , respectively. Similar results are obtained for all the 
cases and results are tabulated in Table 6. The comparison between FEA and DSM are presented in Table 6 and Fig. 11. Except for some of the cases, all the specimens are failed by interactive failure. From the Fig. 11, it is observed that the DSM is conservative for all the series of specimens except for the WSC-CE-F550 series.

\section{New design equation}

Figures 8 and 11 shows the variation of $P_{\text {ANSYS }}$ and $P_{n, \text { DSM }}$ for WSC-UE- $\lambda$ and WSC-CE- $\lambda$ series, respectively. It is observed, DSM provides unconservative results for WSC-CE-F550 series. Figure 12 shows the relationship between FEA and DSM results for all the series of specimens considered in this study. To determine the accurate strength of web stiffened cold formed steel channel column, a new design equation is proposed.

Ultimate strength of web stiffened channel column

$P_{\text {Prop }}=0.793 P_{n, \text { DSM }}+14.66$

Accuracy of the proposed design equation is verified with the test results available from the literature as shown in Table 7. The comparisons of the proposed DSM equation with experimental results available from the literature (Yan and Young 2002; Yap and Hancock 2008) are shown in Table 7. The mean and standard deviation of $P_{\text {EXP }} / P$ pro are 1.03 and 0.07 , respectively. It is clearly shown that the proposed design equation are able to predict the strength of the web stiffened cold formed steel channel columns more accurately than that the DSM equations.

\section{Conclusions}

An experimental and numerical investigation of the structural response of the web stiffened cold formed steel channel columns with various types of edge stiffener has been presented in this paper. A nonlinear finite element technique was developed and validate with the experimental results. A good conformity has been achieved between test and FEA. The validated finite element technique was used to analyze a total of $67 \mathrm{web}$ stiffened cold formed steel channel columns with various types of edge stiffener failed by interactive buckling. The result obtained from the parametric studies was compared with the Direct Strength Method (DSM) for cold formed steel structures. The comparison shows that DSM equation was over estimate the interactive modes of buckling. Hence, new design equation was proposed, and also it was validated with the test results available from the literature.
Open Access This article is distributed under the terms of the Creative Commons Attribution 4.0 International License (http://crea tivecommons.org/licenses/by/4.0/), which permits unrestricted use, distribution, and reproduction in any medium, provided you give appropriate credit to the original author(s) and the source, provide a link to the Creative Commons license, and indicate if changes were made.

\section{References}

Dinis PB, Camotim D (2011) Local/distortional/global mode interaction in simply supported cold-formed steel lipped channel columns. Int J Struct Stab Dyn 11(5):877-902. doi:10.1142/ S0219455411004385

GB 50018-2002 (2002) Technical code of cold-formed thin-walled steel structures. Beijing, China

He Z, Zhou X, Liu Z, Chen M (2014) Post-buckling behaviour and DSM design of web-stiffened lipped channel columns with distortional and local mode interaction. Thin-Walled Struct 84:189-203. doi:10.1016/j.tws.2014.07.001

Institute American Iron Steel (2007) AISI-S100 2007. North American specification for the design of cold-formed steel structural members. Washington, DC

Kwon YB, Hancock GJ (1992) Test of cold-formed channels with local and distortional buckling. J Struct Eng 118(7):1786-1803. doi:10.1061/(ASCE)0733-9445(1992)118:7(1786)

Kwon YB, Kim BS, Hancock GJ (2009) Compression tests of high strength cold-formed steel channels with buckling interaction. J Constr Steel Res 65:278-289. doi:10.1016/j.jcsr.2008.07.005

Manikandan P, Arun N (2016) Numerical investigation on coldformed steel lipped channel columns with intermediate web stiffeners. J Inst Eng (India) 97(1):1-7. doi:10.1007/s40030-0160148-0

Martins AD, Dinis PB, Camotim D, Providência P (2015) On the relevance of local-distortional interaction effects in the behaviour and design of cold-formed steel columns. Comput and Struct 160:57-89. doi:10.1016/j.compstruc.2015.08.003

Wang C, Zhang Z, Zhao D, Liu Q (2016) Compression tests and numerical analysis of web-stiffened channels with complex edge stiffeners. J Constr Steel Res 116:29-39. doi:10.1016/j.jcsr.2015. 08.013

Yan J, Young B (2002) Column tests of cold-formed steel channels with complex stiffeners. J Struct Eng 128(6):737-745. doi:10. 1061/(ASCE)0733-9445(2002)128:6(737)

Yang D, Hancock GJ (2004) Compression tests of high strength steel channel columns with interaction between local and distortional buckling. J Struct Eng 130(12):1954-1963. doi:10.1061/ (ASCE)0733-9445(2004)130:12(1954)

Yap DCY, Hancock GJ (2008) Experimental study of complex highstrength cold- formed cross-shaped steel sections. J Struct Eng 134(8):1322-1333. doi:10.1061/(ASCE)0733-9445(2008)134: $8(1322)$

Yap DCY, Hancock GJ (2011) Experimental study of high-strength cold-formed stiffened-web C-sections in compression. J Struct Eng 137(2):162-172. doi:10.1061/(ASCE)ST.1943-541X. 0000271

Young B, Yan J (2002) Channel columns undergoing local, distortional and overall buckling. J Struct Eng 128(6):728-736. doi:10. 1061/(ASCE)0733-9445(2002)128:6(728)

Young B, Silvestre N, Camotim D (2013) Cold-formed steel lipped channel columns influenced by local-distortional interaction: strength and DSM design. J Struct Eng 139(6):1059-1074. doi:10.1061/(ASCE)ST.1943-541X.0000694 